\section{Rubella antibody screening during pregnancy in an urban area of Northern Italy}

\author{
Massimo De Paschale, ${ }^{1}$ \\ Maria Teresa Manco, ${ }^{1}$ Alessia Paganini, \\ Carlo Agrappi,' Paola Mirri," \\ Gabriella Cucchi, ${ }^{2}$ Barbara Saccani, ${ }^{2}$ \\ Alberto Flores D'Arcais, \\ Pierangelo Clerici ${ }^{1}$ \\ 1 Microbiology Unit and 2 Pediatric and \\ Neonatal Unit, Hospital of Legnano, \\ Milan, Italy
}

\section{Abstract}

Various countries have implemented antirubella vaccination campaigns with the main aim of preventing congenital infection. In 2003, Italy joined the European WHO programme for the elimination of congenital rubella and issued a special healthcare plan, one of the objectives of which was to reduce the proportion of rubella-susceptible pregnant women to less than $5 \%$ by 2005 . The aim of this study was to determine the percentage of seronegative pregnant women after the implementation of this plan. Anti-rubella IgG and IgM antibodies were sought in 2385 pregnant women who attended our hospital for serological screening between 1 July 2008 and 30 June 2010 . They included 750 women of foreign origin (31.4\%). Eight percent of the women were anti-rubella seronegative: $6.2 \%$ of the Italians and $11.7 \%$ of the non-Italians. Among the women of foreign origin, the percentage of seronegativity ranged from $5.6 \%$ of those coming from Eastern Europe to $17.7 \%$ of those coming from Latin America. The level of seropositivity among women of Italian origin is high, although the objective of ensuring less than $5 \%$ of susceptible pregnant women has not yet been quite reached in our area. However, particular attention needs to be given to women coming from geographical areas characterised by different epidemiologies and vaccination strategies because the percentage of seronegativity is in some cases double that of Italian women.

\section{Introduction}

Rubella infection generally leads to mild disease in children, but, if it occurs during early pregnancy, it can cause miscarriages or severe fetal malformations. ${ }^{1}$ The risk of foetal damage is greatest in the first trimester of pregnancy, but rapidly decreases after the twelfth week to only rare cases of deafness due to infections occurring during the $17^{\text {th }}$ and $18^{\text {th }}$ week. $^{2}$

In order to prevent the onset of congenital rubella syndrome (CRS), various European countries have introduced vaccination campaigns based on two main strategies (or a combination of the two): the selective vaccination of adolescent girls and/or women of childbearing age, or the universal vaccination of boys and girls. $^{3}$ In the first case, the selective vaccination of adolescent girls leaves susceptible males who may be responsible for continuing the circulation of the virus that can infect pregnant women who may not have been vaccinated. In the second case, inadequate vaccine coverage may allow the continuing circulation of the virus, prolong the time intervals between epidemics, lead to a higher incidence of the disease among older subjects, including women of childbearing age, and increase the risk of CRS. ${ }^{4,5}$ According to the WHO, at least $95 \%$ of children of both sexes need to be vaccinated before the transmission of rubella can be stopped.

The European WHO therefore issued a plan for eliminating congenital rubella ${ }^{6}$ with the aim of having less than one case of CRS per 100,000 live births by 2010 . In order to reach this goal, it was planned to ensure at least 95\% vaccine coverage among children aged 2 years, with at least one dose of vaccine in all administration units. ${ }^{7}$ Furthermore, additional vaccination strategies were foreseen for adolescents, women of childbearing age and immigrants, as well as recovery strategies for those children who were not vaccinated before. ${ }^{?}$

The vaccine was introduced into Italy at the beginning of the 1970s. Vaccination was initially recommended only for prepubescent girls (Ministerial Decree of 6 April 1976). The introduction of recombinant measles, mumps and rubella (MMR) vaccines in the 1990s led to the recommendation that all children of both sexes should be vaccinated before they are two years old (Ministerial Decree of 6 June 1995), and that their immunisation status should be assessed (and regularised if necessary) at the ages of 5-6 and 11-12 years, when they are administered other vaccines in accordance with the national vaccination schedule (Ministerial Decrees of 7 April 1999 and 13 July 1999).

Studies carried out in the 1990s estimated that about $56 \%$ of children were immunized with combined measles, mumps and rubella vaccine, depending on the region (vaccination coverage greater in Northern than in Southern Italy); ${ }^{8-11}$ this was reflected by the lower seronegative rates of women of childbearing age in Northern than in Southern Italy ( $6 \%$ vs $12 \%) .{ }^{12}$ By 2003, regional immunisation rates had increased to between $55 \%$ and $90 \%{ }^{9}$

In the same year, Italy joined the WHO European programme for the elimination of
Correspondence: Massimo De Paschale, Microbiology Unit, Hospital of Legnano, via Papa Giovanni Paolo II, 20025 Legnano (Milan), Italy. Tel. +39.0331.449319 - Fax: +39.0331.449578.

E-mail: massimo.depaschale@ao-legnano.it

Key words: antibodies, pregnancy, screening, rubella, vaccination

Contributions: all authors have contributed substantially to conception and design of study, acquisition, analysis and interpretation of data; to drafting the article and revising it critically for important intellectual content; and on final approval of the version to be published.

Conflict of interest: the authors report no conflicts of interest.

Received for publication: 15 September 2011. Revision received: 16 November 2011.

Accepted for publication: 27 December 2011.

This work is licensed under a Creative Commons Attribution NonCommercial 3.0 License (CC BYNC 3.0).

(C) Copyright M. De Paschale et al., 2012

Licensee PAGEPress srl, Italy

Infectious Disease Reports 2012; 4:e17

doi:10.4081/idr.2012.e17

congenital rubella ${ }^{6}$ and issued a special healthcare plan (Agreement between the Central Government, Regions and autonomous Provinces of Trento and Bolzano regarding the National Measles and congenital Rubella Elimination Plan, 2003-2007. Unpublished data). The aims of this plan were to ensure that an average of $95 \%$ of children aged less than two years had received a dose of MMR by 2006 , and to reduce the proportion of rubellasusceptible pregnant women to less than $5 \%$ by 2005 . It was also planned to vaccinate children aged more than two years and any adolescents who were still susceptible by undertaking an extraordinary recovery programme and introducing a second dose of MMR vaccine. The strategies aimed at women of childbearing age were to vaccinate susceptible women before they became pregnant; to screen pregnant women for anti-rubella antibodies as early as possible and, if they were seronegative, to repeat the screening every 4-6 weeks at least until the fifth month; and to vaccinate susceptible women during the postpartum period. Particular attention was also given to protecting recent immigrants who have reduced access to healthcare services.

The aim of this study was to determine the percentage of susceptible pregnant women in the period 2008-2010 in order to verify whether this objective of the plan had been reached in our area located in Lombardy, a region of Northern Italy. 


\section{Materials and Methods}

Between 1 July 2008 and 30 June 2010, 2385 pregnant women underwent a first serological screening for anti-rubella IgG and IgM antibodies: 2255 (94.5\%) were in the first trimester of pregnancy, $69(2.9 \%)$ in the second and 61 $(2.6 \%)$ in the third. Seven hundred and fifty

(31.4\%) were non-Italians: 251 came from Eastern Europe, 171 from the Middle East and the Maghreb, 130 from Latin America, 66 from the Indian sub-continent, 58 from China and the Far East, 55 from South-Equatorial Africa, and 19 from Western Europe.

Anti-rubella IgG and IgM antibodies were detected by means of enzyme linked immunoassays (ETI-RUBEK-G PLUS and ETIRUBEK-M reverse plus, DiaSorin, Saluggia, Italy). Cut-off value used for the determination of IgG levels was $10 \mathrm{IU} / \mathrm{mL}$. IgM positivity was confirmed by means of an ezyme-linked fluorescent assay (ELFA; VIDAS RUB IgM, BioMérieux, Marcy l'Etoile, France); in addition, IgG avidity was determined by modifying the IgG detection test (VIDAS, RUB IgG II, BioMérieux, Marcy l'Etoile, France) as suggested by Eggers. ${ }^{13}$ In the case of IgM positivity, the woman's general practitioner was contacted and advised to evaluate the case and refer the patient to a Reference Centre.

The data were statistically analysed using the $\chi^{2}$ test, Fisher's exact test, and Student's t test.

\section{Results}

Two thousand, one hundred and ninety-five women (92.0\%) were IgG positive and 10 (0.4\%) IgM positive (all in the first trimester of pregnancy); ELFA confirmed eight of the IgMpositive cases. All of these women had high levels of IgG avidity. Their general practitioners were contacted and the women were referred to a Reference Centre. We had information on only 4 of 8 women, all excluding an infection during pregnancy. The 4 women had their delivery in our hospital and the children are currently healthy.

Table 1 shows that the differences in the seroprevalence data between the Italian and non-Italian women were statistically significant in the case of $\operatorname{IgG}(\mathrm{P}<0.01)$, but not in the case of IgM.

Table 2 shows the geometric mean IgG values of the IgG-positive women ( $\geq 10 \mathrm{IU} / \mathrm{mL}$ ); the difference between the women of Italian and foreign origin is statistically significant $(\mathrm{P}<0.01)$.

A total of $8 \%(95 \%$ CI: $6.91-9.09)$ of the women were negative for anti-rubella antibodies: $6.2 \%$ of the Italians (95\% CI: $5.03-7.37$ ), and $11.7 \%$ of the non-Italians (95\% CI: 9.40 $14.00)$. In terms of the country of origin, seronegativity ranged from $5.6 \%$ among the women from Eastern Europe to $17.7 \%$ among those from Latin America (Table 3). All of the differences from the $6.2 \%$ of Italian women are statistically significant except in the case of the women coming from the Indian sub-continent and rest of Europe.

In relation to age, the differences between the Italian and non-Italian women are statistically significant only in the age group 21-30 years (Table 4). Within the two groups of Italian and non-Italian women, the differences between the various age groups are not statistically significant.

\section{Discussion}

In 2003, Italy joined the European WHO programme aimed at eliminating congenital rubella by $2010^{6}$ and issued a special healthcare plan. Among other things, this plan had the objectives of ensuring that there would be at least $95 \%$ vaccination coverage by the end of the second year of life and that fewer than $5 \%$ of pregnant women would be susceptible to the disease. As far as the first objective is concerned, partial data of the Ministry of Health for 2009 indicate a general coverage of $89.9 \%$, with regional variations of between $70.8 \%$ and 95.5\% (94.8\% in Lombardy, www.salute.gov.it). Before the implementation of the plan, seroprevalence among women of childbearing age and pregnant women in Italy was about $90 \%$, with higher values in Northern than in Southern Italy. ${ }^{10,11,14,15}$ These data were in line with European data indicating higher seroprevalence levels in Northern than in Southern Europe. ${ }^{12,16-18}$

Since the implementation of the healthcare plan in our area, the seroprevalence level among pregnant women has been high (92\%) without any differences between age groups, but has not substantially changed from before its implementation. ${ }^{12}$ The objective of ensuring that fewer than $5 \%$ of pregnant women are susceptible to the disease has therefore not yet been reached although it is near (about 6\%). It is necessary to bear in mind that only one dose was administered in Italy in the past and, although the difference is slight, one dose is less efficacious than two. ${ }^{19}$ Furthermore, as what is observed today is the result of vaccinations given some time ago, the antibodies may have been lost. It is known that antibody levels decline over time after vaccination and after natural infection; minimal annual antibody decay rates of $-2.9 \%$ was reported in the literature $^{20}$ although, 15-20 years after vaccination, rubella seropositivity still ranges from $92 \%$ to $97 \% .^{21-23}$

However, when comparing published data, it is important to consider the antibody titre used as an index of positivity. For example, in one study conducted 20 years after vaccination (with two doses), all of the subjects were considered positive with levels of more than 4 IU/mL; however, $17 \%$ had levels of less than 10 $\mathrm{IU} / \mathrm{mL}$ and $36 \%$ had levels of less than 15 $\mathrm{IU} / \mathrm{mL} .^{24}$ As it has been suggested that protection is provided by levels of $10-15 \mathrm{IU} / \mathrm{mL}^{25,26}$ because women with lower antibody values can still be considered at risk of developing CRS, we defined positivity as levels of $\geq 10$ IU/mL. Consequently, the fact that $6 \%$ of our Italian women were seronegative may have been due to their missing the vaccination programme, an incomplete antibody response, or a decline in antibodies over time. Further-

Table 1. Seropositivity for anti-rubella IgG in pregnant women of Italian and foreign origin (2008-2010).

\begin{tabular}{lccccccc} 
Origin & No. & $\begin{array}{c}\operatorname{IgG} \\
\text { positive }\end{array}$ & $\%$ & $\begin{array}{c}\text { Anti-rubella antibodies } \\
95 \% \text { CI }\end{array}$ & $\begin{array}{c}\text { Confirmed } \\
\text { IgM positive }\end{array}$ & $\%$ & $95 \%$ CI \\
Italian & 1635 & 1533 & 93.8 & $92.63-94.97$ & 7 & 0.4 & $0.09-0.71$ \\
Foreign & 750 & 662 & 82.3 & $79.57-85.03$ & 1 & 0.1 & $0.00-0.33$ \\
\hline P & & & $<0.01$ & & & NS & \\
Total & 2385 & 2195 & 92.0 & $90.91-93.09$ & 8 & 0.3 & $0.08-0.52$ \\
\hline
\end{tabular}

NS, not significant

Table 2. Geometric mean IgG values in pregnant women of Italian and foreign origin who were positive for anti-rubella IgG $(\geq 10 \mathrm{IU} / \mathrm{mL})$.

\begin{tabular}{lccc} 
Origin & No. & \multicolumn{2}{c}{$\begin{array}{c}\text { Anti-rubella antibodies (IU/mL) } \\
\text { Ceometric mean }\end{array}$} \\
$\begin{array}{lccc}95 \% \mathrm{CI} \\
\text { Italian }\end{array}$ & 58.5 & $56.7-60.4$ \\
Foreign & 1533 & 51.7 & $49.2-54.4$ \\
\hline P & 662 & $<0.01$ & \\
Total & 2195 & 56.4 & $54.9-57.9$ \\
\hline
\end{tabular}


more, this value is in line with the WHO directives indicating the need to ensure $>90 \%$ vaccination coverage in women of childbearing age. ${ }^{27}$

Things are different in the case of nonItalian women coming from countries with different epidemiologies and vaccination strategies. Increasing immigration involves the arrival of women coming from areas where the level of vaccination may be lower, which increases the pool of seronegative women. We found that percentage seronegativity among the women of foreign origin in our study was in some cases more than double that among Italian women. This a well-known problem in Europe: ${ }^{18,28}$ the European WHO has made it the subject of specific indications, ${ }^{7}$ and it was emphasised in the healthcare plan of the Italian Ministry of Health. Our own findings underline its importance because almost onethird of the pregnant women were born abroad, which is in line with official Italian data showing that, over the last few years, there has been an increase in immigration above all from nonEU countries. ${ }^{29}$ It is therefore necessary to make further efforts in this direction as the antibody screening and the vaccination of all women of childbearing age, new mothers and women who make a termination of pregnancy who have no serologic evidence of immunity or a documented vaccination.

In relation to acute infection, we found that $0.3 \%$ of our pregnant women were IgM positive, with no significant difference between the Italian and non-Italian group. However, as it has been reported that the IgM test can lead to false-positive results in patients with other ongoing infections (parvovirus or mononucleosis) or rheumatoid factor, ${ }^{30}$ and that IgM antibodies may remain for as long as one year or more after a first natural infection, asymptomatic re-infection or vaccination, ${ }^{31,32}$ we determined IgG avidity. ${ }^{33-34}$ All of our IgM-positive women showed a high level of IgG avidity which, given the test used and the time of sampling, suggested an infection occurring before conception. However, given the variability of IgG maturation (which may be brief in some cases), ${ }^{33-35}$ we referred the patients to Reference Centres for further investigation. Unfortunately, we had information about only half of these cases which, nevertheless,

Table 3. Seronegativity for anti-rubella IgG in pregnant women by geographical origin (2008-2010).

\begin{tabular}{lccccc} 
Origin & No. & $\begin{array}{c}\text { Anti-rubella } \\
\text { antibodies } \\
\text { Negative }\end{array}$ & \% & 95\% CI & \\
Africa & 55 & 8 & 14.5 & $5.19-23.81$ & $<0.05$ \\
China and the Far East & 58 & 10 & 17.2 & $7.49-26.91$ & $<0.01$ \\
\hline Eastern Europe & 251 & 14 & 5.6 & $2.76-8.44$ & NS \\
Western Europe & 19 & 3 & 15.8 & $0.00-32.20$ & NS \\
\hline Indian sub-continent & 66 & 5 & 7.6 & $1.21-13.99$ & NS \\
Middle East and the Maghreb & 171 & 25 & 14.6 & $9.31-19.89$ & $<0.01$ \\
\hline Latin America & 130 & 23 & 17.7 & $11.14-24.26$ & $<0.01$ \\
Italy & 1635 & 102 & 6.2 & $5.03-7.37$ & \\
\hline
\end{tabular}

*vs Italian women; NS, not significant

Table 4. Seronegativity for anti-rubella IgG in pregnant women of Italian and foreign origin by age (2008-2010).

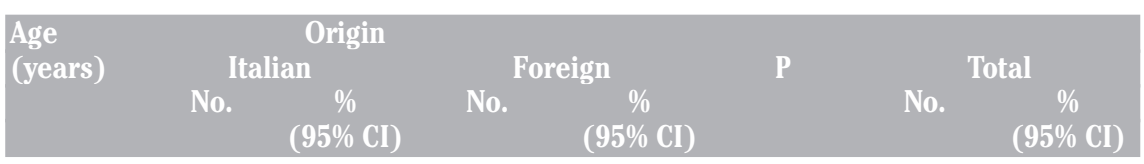

8.0

\begin{tabular}{|c|c|c|c|c|c|c|c|}
\hline$\leq 20$ & $2 / 25$ & $(0.00-18.63)$ & $4 / 35$ & $(0.87-21.93)$ & NS & $6 / 60$ & $(2.41-17.59)$ \\
\hline $21-30$ & $30 / 490$ & $\begin{array}{c}6.1 \\
(3.98-8.22)\end{array}$ & $56 / 415$ & $\begin{array}{c}13.5 \\
(10.21-16.79)\end{array}$ & $<0.01$ & $86 / 905$ & $\begin{array}{c}9.5 \\
(7.59-11.41)\end{array}$ \\
\hline $31-40$ & $63 / 1050$ & $\begin{array}{c}6.0 \\
(4.56-7.44)\end{array}$ & $26 / 282$ & $\begin{array}{c}9.2 \\
(5.83-12.57)\end{array}$ & NS & $89 / 1332$ & $\begin{array}{c}6.7 \\
(5.36-8.04)\end{array}$ \\
\hline$>40$ & $7 / 70$ & $\begin{array}{c}10.0 \\
(2.97-17.03)\end{array}$ & $2 / 18$ & $\begin{array}{c}11.1 \\
(0.00-25.61)\end{array}$ & NS & $9 / 88$ & $\begin{array}{c}10.2 \\
(3.88-16.52)\end{array}$ \\
\hline Total & $102 / 1635$ & $\begin{array}{c}6.2 \\
(5.03-7.37)\end{array}$ & $88 / 750$ & $\begin{array}{c}11.7 \\
(9.40-14.00)\end{array}$ & $<0.01$ & $190 / 2385$ & $\begin{array}{c}8.0 \\
(6.91-9.09)\end{array}$ \\
\hline
\end{tabular}

excluded an infection during pregnancy and this was supported by the birth in our hospital of currently healthy children.

In conclusion, our data show high levels of anti-rubella antibodies among Italian pregnant women in our area. However, particular attention should be paid in the case of women coming from geographical areas with different epidemiologies and vaccination strategies, whose access to healthcare services may be reduced for various reasons, such as language, culture, bureaucracy, etc. In these cases, special efforts need to be made to overcome these gaps and facilitate the antibody screening and vaccination.

\section{References}

1. Mellinger AK, Cragan JD, Atkinson WL, et al. High incidence of congenital rubella syndrome after a rubella outbreak. Pediatr Infect Dis J 1995;14:573-8.

2. Cooper LZ, Altford CA, Rubella. In: Remington JS,Klein J0, Baker C, Wilson $\mathrm{C}$, editors. Infectious diseases of the fetus and newborn infant. Philadelfia: Elsevier Saunders; 2006. p.893-926.

3. World Health Organization. Report of a meeting on preventing congenital rubella syndrome: immunization strategies, surveillance needs, Geneva, 12-14 January 2000. Geneva, World Health Organization, 2000. Available from: https://extranet.who. int/ivb_docs/documents/1928

4. Anderson RM, May RM. Vaccination against rubella and measles: quantitative investigations of different policies. J Hyg 1983;90:259-325.

5. WHO. Rubella vaccines: WHO position paper. Wkly Epidemiol Rec 2011;86:301-16.

6. European Health for All Series. Health21: The health for all policy framework for the WHO European Region 1999;6:49.

7. World Health Organization. Eliminating measles and rubella and preventing congenital rubella infection. WHO European Region strategic plan 2005-2010. Copenhagen, Denmark: WHO Regional Office for Europe, 2005.

8. Salmaso S, Rota MC, Ciofi degli Atti ML, et al. Infant immunization coverage in Italy: estimates by simultaneous EPI cluster surveys of regions. Bull World Health Organ 1999;77:843-51.

9. Ciofi degli Atti ML, Rota MC, Bella A, et al. Do changes in policy affect vaccine coverage levels? Results of a national study to evaluate childhood vaccination coverage and reasons for missed vaccination in Italy. Vaccine 2004;22:4351-7.

10. Gabutti G, Rota MC, Salmaso S, et al. Epidemiology of measles, mumps and 
rubella in Italy. Epidemiol Infect 2002;129: 543-50.

11. Rota MC, Bella A, Gabutti G, et al. Rubella seroprofile of the Italian population: an 8year comparison. Epidemiol Infect 2007; 135:555-62.

12. Pebody RG, Edmunds WJ, Conyn van Spaendonck M, et al. The seroepidemilogy of rubella in Western Europe. Epidemiol Infect 2000;125:347-57.

13. Eggers M, Enders M, Strobel S, et al. A novel and rapid method for determination of rubella virus immunoglobulin $\mathrm{G}$ avidity. Clin Microbiol Infect 2005;11Suppl2:33.

14. Giambi C, Rota MC, Bella A, et al. Rubella epidemiology in Italy in the years 19982004. Ann Ig 2007;19:93-102.

15. Lo Giudice D, Cannavò G, Capua $\mathrm{A}$, et al. Eliminating congenital rubella: a seroepidemiological study on women of childbearing age and MMR vaccine coverage in newborns. J Prev Med Hyg 2009;50:236-40.

16. Gonçalves G, Nascimento MS, Réu C, Cutts FT. Levels of rubella antibody among vaccinated and unvaccinated Portuguese mothers and their newborns. Vaccine 2006;24: 7142-7.

17. Dominguez A, Plans P, Espuňes J, et al. Rubella immune status of indigenous and immigrant pregnant women in Catalonia, Spain. Europ J Public Health 2007;17:5604.

18. Kakoulidou M, Forsgren M, LewensohnFuchs I, Johansen K. Serum levels of rubella-specific antibodies in Swedish women following three decades of vaccination programmes. Vaccine 2010;28:1002-7.

19. Davidkin I, Peltola H, Leinikki P, Valle M.
Duration of rubella immunity induced by two-dose measles, mumps and rubella (MMR) vaccination. A 15-year follow-up in Finland. Vaccine 2000;18:3106-12.

20. Kremer JR, Schneider F, Muller CP. Waning antibodies in measles and rubella vaccinees-a longitudinal study. Vaccine 2006;24:2594-601.

21. 0'Shea S, Woodward S, Best JM, et al. Rubella vaccination: persistence of antibodies for 10-21 years. Lancet 1988;2:909.

22. King JC, Lichenstein R, Feigelman S, et al. Measles, mumps, and rubella antibodies in vaccinated Baltimore children. Am J Dis Child 1993;147:558-60.

23. Christenson B, Böttiger M. Long-term follow-up study of rubella antibodies in naturally immune and vaccinated young adults. Vaccine 1994;12:41-5.

24. Davidkin I, Jokinen S, Broman M, et al. Persistence of measles, mumps, and rubella antibodies in an MMR-vaccinated cohort: a 20-year follow-up. J Infect Dis 2008;197:950-6.

25. Skendzel LP. Rubella immunity: defining the level of protective antibody. Am J Clin Pathol 1996;106:170-4.

26. Matter L, Kogelschatz K, Germann D. Serum levels of rubella virus antibodies indicating immunity: response to vaccination of subjects with low or undertectable antibody concentrations. J Infect Dis 1997;175:749-55.

27. World Health Organization. Strategic plan for measles and congenital rubella infection in the European Region of WHO. Copenhagen, Denmark: WHO Regional Office for Europe, 2003. Available from: http://www.euro.who.int/en/what-we-do/ health-topics/communicable-diseases/ measles-and-rubella/publications/pre-2009 /strategic-plan-for-measles-and-congenitalrubella-infection-in-the-european-regionof-who

28. Lever AM, Ross MG, Baboonian C, Griffiths PD. Immunity to rubella among women of child-bearing age. Br J Obstet Gynaecol 1987;94:208-12.

29. Caritas-Migrantes Foundation. Immigrazione. Dossier Statistico 2008. XVIII Rapporto. Rome: Edizioni Idos, 2008.

30. Tipples GA, Hamkar R, Mohktari-Azad T, et al. Evaluation of rubella IgM enzyme immunoassays. J Clin Virol 2004;30:233-8.

31. Banatvala JE, Best JM, O'Shea S, Dudgeon JA. Persistence of rubella antibodies after vaccination: detection after experimental challenge. Rev Infect Dis 1985;7(suppl 1): S86-90.

32. Best JM, Banatvala JE, Morgan-Capner P, Miller E. Fetal infection after maternal reinfection with rubella: criteria for defining reinfection. BMJ 1989;299:773-5.

33. Hedman K, Seppälä I. Recent rubella virus infection indicated by a low avidity of specific IgG. J Clin Immunol 1988;8:214-21.

34. Enders G, Knotek F. Rubella IgG total antibody avidity and IgG subclass-specific antibody avidity assay and their role in the differentiation between primary rubella and rubella reinfection. Infection 1989;17:21826.

35. Böttiger B, Jensen IP. Maturation of rubella IgG avidity over time after acute rubella infection. Clin Diagn Virol 1997;8:105-11. 